\title{
Oviposição e desenvolvimento de Brachycephalus ephippium (Spix) (Anura, Brachycephalidae)
}

\author{
José P. Pombal Jr. ${ }^{1}$
}

\begin{abstract}
Oviposition and development of pumpkin toadlet, Brachycephalus ephippium (Spix) (Anura, Brachycephalidae). The Pumpkin toadlet, Brachycephalus ephippium (Spix, 1824), is an orangish daily anuran, which inhabits the litter of the Atlantic Forest of Southeastern Brazil. During a survey of this species' natural

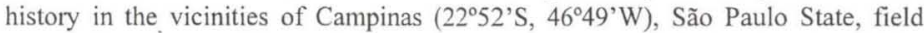
observations were made on the oviposition behavior, in which after the male left the oviposition site, the female covered the surface of all eggs with soil particles. She pressed and rolled each egg against the ground using her hindfeet, until the eggs were indistinguishable from the litter background. A clutch was obtained in laboratory and two others were found in the field. After 25 days of development the embryo possess a big yolk sac, differentiated mouth and a small tail with caudal membranes poorly developed. After 41 days, fingers and toes are fully formed, the tail is relatively smaller than the previous state, the abdomen is large due to the yolk within, and the mouth possess two egg tooth. After 54 days, the tail remains as a small appendix, there is only one egg teeth, and body is densely pigmented. The hatchling occurred after 64 days of development, the young possess reddish brown coloration, vestigial tail, and no egg teeth.

KEY WORDS. Brachycephalidae, Brachycephalus, development, oviposition behavior, anuran
\end{abstract}

O desenvolvimento larvário em anfíbios anuros geralmente ocorre em ambiente aquático, embora possa ocorrer em outros ambientes (DUELLMAN \& TRUEB 1986). Anuros como Eleutherodactylus Duméril \& Bibron, 1841 (Leptodactylidae), que vivem na serrapilheira da floresta, cuja umidade é elevada, podem ter ovos grandes com muita reserva e desenvolvimento direto (LUTZ 1949). Como em Eleutherodactylus, o braquicefalídeo Brachycephalus ephippium (Spix, 1824) também apresenta ovos grandes e com grande quantidade de vitelo (POMBAL et al. 1994).

Composta por dois gêneros, Brachycephalus Fitzinger, 1826 e Psyllophryne Izecksohn, 1971, a família Brachycephalidae Günther é restrita a Floresta Atlântica entre os Estados do Espírito Santo e Paraná (Pombal et al. 1998). Psyllophryne didactyla Izecksohn, 1971 e $P$. hermogenesi Giaretta \& Sawaya, 1998 são as únicas espécies reconhecidas para o gênero, sendo poucas as informações sobre o modo de vida (IZECKSOHN 1971; GIARETTA \& SAWAYA 1998). Até recentemente, Brachycephalus era considerado gênero monotípico (FrosT 1985; DUELLMAN \& TRUEB 1986). Recentemente, Brachycephalus nodoterga Miranda-Ribeiro 1920 foi revalidado (Heyer et al. 1990) e uma espécie foi descrita: B. pernix Pombal, Wistuba \& Bornschein, 1998. Pouco é conhecido sobre a biologia das espécies da

1) Departamento de Vertebrados, Museu Nacional. Quinta da Boa Vista, 20940-040 Rio de Janeiro, Rio de Janeiro, Brasil. Bolsista do CNPq. 
família Brachycephalidae, existindo apenas o trabalho de POMBAL et al. (1994) sobre o comportamento reprodutivo de B. ephippium. Na presente comunicação são descritos os embriões, o jovem recém-eclodido, a desova e o comportamento de oviposição de Brachycephalus ephippium.

\section{MATERIAL E MÉTODOS}

Desovas e embriões de B. ephippium foram obtidos em um fragmento de

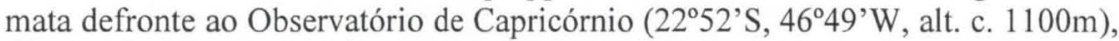
distrito de Joaquim Egídio na divisa dos municípios de Campinas e Morungaba, Estado de São Paulo. É uma mata secundária, mesófila semidecídua localizada na Serra das Cabras, um contraforte da Serra da Mantiqueira. O terreno dentro da mata é acidentado e o substrato pode apresentar uma fina camada de serapilheira (às vezes ausente) bem como locais com grande acúmulo de material vegetal em decomposição. Na região são comuns blocos de granito de vários tamanhos, que têm sido explorados comercialmente, o que ocasionou a derrubada de trechos da vegetação, causando assoreamento do riacho. Alguns trechos da mata estão alterados devido a diminuição do número de árvores que formam o dossel e o aumento de plantas invasoras, como taquaras.

Além de Brachycephalus ephippium, outras espécies de anfíbios anuros foram observadas no local estudado: os Leptodactylidae Eleutherodactylus binotatus (Spix, 1824), E. guentheri (Steindachner, 1864), E. juipoca Sazima e Cardoso, 1978, Hylodes sazimai Haddad \& Pombal, 1995 e o Hylidae Hyla luctuosa Pombal \& Haddad, 1993. Eleutherodactylus spp. e Hyla luctuosa usaram a serapilheira como abrigo, uma vez que podiam ser encontrados durante a procura de $B$. ephippium.

As observações de comportamento foram feitas utilizando o método "todas as ocorrências" ( $c f$. LEHNER 1996). Alguns comportamentos foram documentados em fotografias (diapositivos), para análise mais detalhada. As desovas e embriões de B. ephippium foram obtidas durante as observações de campo para um trabalho mais amplo sobre a biologia da espécie (POMBAL et al. 1994).

No dia 20 de novembro de 1990, uma desova foi cercada (oviposição observada no dia anterior) para que o período de desenvolvimento dos ovos pudesse ser acompanhado no próprio ambiente. $\mathrm{O}$ cercado, com $7 \mathrm{~cm}$ de diâmetro, foi construído com armação de arame recoberta com tela plástica (Fig. 1), para evitar fuga dos indivíduos recém-eclodidos, e coberto com cascas de árvores, para manter condição semelhante àquela em que a desova foi encontrada.

Duas desovas foram encontradas no ambiente, de cada uma delas dois ovos foram fixados para observar o desenvolvimento dos embriões em diferentes estágios (não foi possível examiná-los sem que antes fossem limpos; veja resultados). Um ovo foi fixado aos 25 dias de desenvolvimento e outro aos 54 dias, ambos da desova obtida em 19 de novembro de 1990. Desta desova, que foi cercada, dois ovos chegaram a eclosão (um ovo foi perdido). Na desova obtida em 7 de fevereiro 1991, dois ovos foram fixados aos 29 e 41 dias de desenvolvimento, respectivamente. Os diferentes embriões foram medidos com ocular micrométrica sob estereomicroscópio. Os ovos e embriões fixados foram fotografados sob estereomicrocópio, para documentação. 
Os embriões e jovens recém-eclodidos de B. ephippium estão depositados na coleção de anfíbios do Museu Nacional, Universidade Federal do Rio de Janeiro, Rio de Janeiro, Brasil (MNRJ); espécimes adultos estão depositados na coleção Célio F. B. Haddad (CFBH), no Departamento de Zoologia da Universidade Estadual Paulista, em Rio Claro, São Paulo, Brasil, e na coleção de anfíbios do Museu de História Natural (ZUEC), na Universidade Estadual de Campinas, Campinas, São Paulo, Brasil.

\section{RESULTADOS}

\section{Oviposição}

Um casal em amplexo que se alojou sob cascas de árvore, foi observado às 8:59h (não foi considerado o horário de verão neste estudo) do dia 19 de novembro de 1990. O macho mudou o tipo de amplexo (antes inguinal), passando a segurar a fềmea na região mediana do abdômen (PoMBAL et al. 1994). O casal permaneceu imóvel por mais de trinta minutos, até que o macho afastou as pernas mantendo-as apoiadas no substrato (POMBAL et. al. 1994). A oviposição durou cerca de trinta minutos e a fêmea apresentava-se "emagrecida" ao seu término. Às 10:30h o macho abandonou a fêmea, que permaneceu estacionária, com um ovo junto à sua cloaca. Doze minutos após o macho retirar-se, a fêmea, com o auxílio das pernas, puxou os ovos para sob seu corpo e, utilizando a região plantar, rolou os ovos contra o substrato num movimento de vai e vem (a superfície do ovo manipulado chegava a deformar devido a pressão exercida pelo pé). Estes movimentos eram repetidos de duas a seis vezes (uma seqüência de seis movimentos durou onze segundos) e em cada seqüência, a perna utilizada podia ou não ser alternada. Além desses movimentos, a fềmea girava o corpo sobre os ovos, desta forma alternando os ovos manipulados.

Seis minutos após o início da manipulação dos ovos, a fêmea havia girado $180^{\circ} \mathrm{e}$ ao final de onze minutos o giro sobre o ovos completou $360^{\circ}$. O movimento giratório sobre os ovos podia ser para a direita ou para a esquerda. Os giros foram sempre acompanhados da movimentação de pernas, que faziam os ovos rolarem. Num certo momento, os movimentos das pernas pareciam estar forçando os ovos para baixo (sem rolar). Após esta fase, a fêmea, sempre girando, passou a arrastar partículas do substrato por sobre os ovos, com movimentos das pernas.

Cerca de sete minutos após o início dos movimentos que forçavam os ovos para baixo, a fềmea voltou a rolar os ovos. Mesmo depois dos ovos estarem cobertos por partículas do substrato, a fêmea continuou os movimentos giratórios sobre a desova por mais 90 minutos. Num dado momento, a fêmea foi retirada (para fotografia da desova) e, após recolocada, retornou aos cuidados que tinha antes desta interferência.

\section{Características dos ovos e da desova}

Um desova obtida em laboratório, encontrada entre o folhedo do terrário em 27 de outubro de 1989, a partir de indivíduos coletados em Joaquim Egídio, era composta de sete ovos que mediam 5,1 a 5,3 mm de diâmetro. Os ovos apresentavam cor creme e eram envoltos por uma fina membrana com partículas do substrato aderidas. Em menos de duas semanas os ovos deterioraram, sem que fosse possível observar qualquer desenvolvimento em seu interior. 


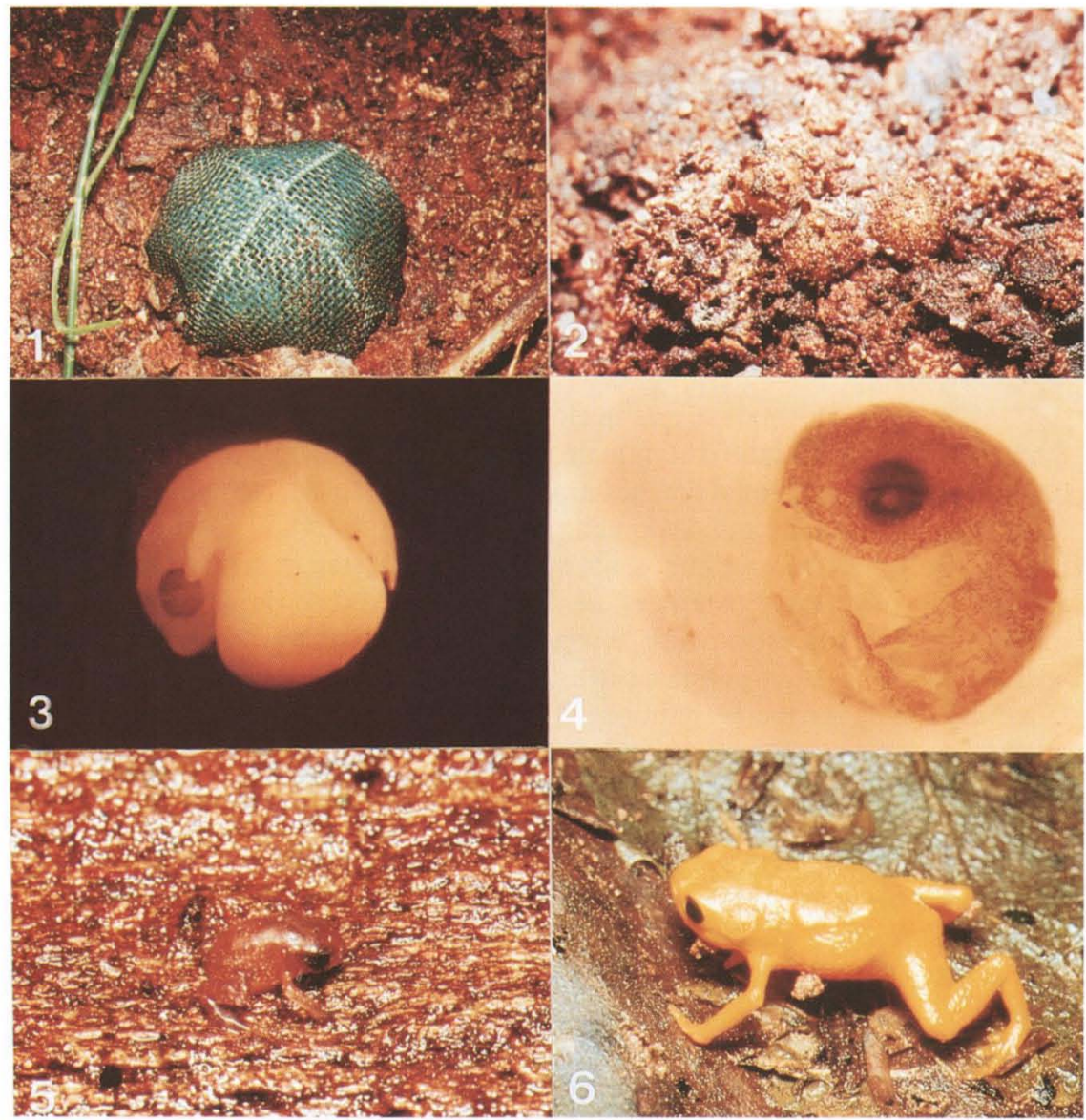

Figs 1-6. (1) Cercado de tela plástica para os ovos de Brachycephalus ephippium. (2-6) B. ephippium procedentes de Joaquim Egídio, Campinas, São Paulo: (2) três ovos encobertos por partículas do substrato; (3) embrião com 25 dias de desenvolvimento; (4) embrião com 45 dias de desenvolvimento; (5) jovem recém-eclodido; (6) macho adulto.

Outra desova, composta também por cinco ovos, foi observada no ambiente em 19 de novembro de 1990. Esta desova, que pôde ser encontrada pelo acompanhamento de um casal em amplexo, foi depositada no chão, entre cascas de árvore em decomposição. Embora os ovos estivessem totalmente cobertos por partículas do substrato (Fig. 2), era possível notar sua coloração amarelada, devido à grande quantidade de vitelo em seu interior.

Uma terceira desova foi encontrada em 7 de fevereiro de 1991 numa cavidade do substrato. Provavelmente, a fêmea havia desovado há pouco, uma vez que ainda se encontrava sobre três ovos. Devido às características do local desta desova e 
também à camuflagem conferida aos ovos pelas partículas aderidas, é possível que nem todos os ovos tenham sido encontrados.

\section{Desenvolvimento}

Aos 25 dias de desenvolvimento o embrião está curvado sobre o saco vitelínico, que é muito grande (Fig. 3). A boca está diferenciada. Os olhos estão diferenciados mas não completamente formados e estão pouco pigmentados. Membros anteriores e posteriores estão distintos e os dedos e artelhos não estão diferenciados. A cauda é pequena, pouco maior que os membros posteriores; as membranas caudais estão pouco desenvolvidas, sendo a inferior maior que a superior. Na região da cabeça ocorre pigmentação esparsa. $\mathrm{O}$ diâmetro, quando considerado a distância entre o topo da cabeça e a base da cauda, é de $3,1 \mathrm{~mm}$.

Aos 29 dias de desenvolvimento não há diferenças perceptíveis em comparação com o embrião de 25 dias. O diâmetro, quando considerado a distância entre o topo da cabeça e a base da cauda, é de $3,1 \mathrm{~mm}$.

Aos 41 dias de desenvolvimento, os dedos e artelhos estão completamente formados e a cauda é menor que aos 25 dias de desenvolvimento. A boca apresenta dois dentes de ovo; a língua está diferenciada e as narinas, presentes; as pálpebras estão parcialmente formadas. O abdômen é grande em virtude da quantidade de vitelo. $\mathrm{O}$ corpo apresenta pigmento esparso, em menor concentração na região da gula e barriga. O comprimento rostro-anal é $3,2 \mathrm{~mm}$.

Aos 54 dias de desenvolvimento a cauda regrediu a um pequeno apêndice pouco perceptível. O dente de ovo agora é único (Fig. 4), bicúspide. O abdômen, proporcionalmente menor que na fase anterior (41 dias de desenvolvimento), embora ainda seja possível notar o vitelo em seu interior. O corpo é densamente pigmentado, com exceção da barriga que é clara. O comprimento rostro-anal é 4,5 $\mathrm{mm}$.

A eclosão ocorreu aos 64 dias de desenvolvimento. O jovem é semelhante ao embrião de 54 dias de desenvolvimento, a cauda está ainda mais reduzida e o dente de ovo está ausente. O comprimento rostro-anal dos dois jovens é 5,2 e 5,4 $\mathrm{mm}$. A coloração dos jovens recém-eclodidos (menos de 12 horas após o nascimento) é castanho-avermelhado (Fig. 5). A cabeça é pouco mais escura que o dorso e o abdômen castanho-amarelado que, devido a translucidez da pele, permite visualizar o vitelo. Os machos e fêmeas adultos de Brachycephalus ephippium apresentam coloração alaranjadas uniformes (Fig. 6) ou, mais raramente, alaranjado avermelhado por todo o corpo; em alguns indivíduos a extremidade do terceiro dedo pode apresentar-se enegrecida. Um jovem com $8,1 \mathrm{~mm}$ de comprimento rostro-anal [aproximadamente metade do tamanho do adultos (POMBAL et al. 1994)] apresentava coloração alaranjada semelhante à dos adultos.

\section{DISCUSSÃO}

\section{Oviposição}

No gênero Alytes Wagler, 1829 (Discoglossidae), no momento da desova, há troca de amplexo inguinal para axilar (MARQUEZ \& VERREL 1991). De maneira similar, o macho de Brachycephalus ephippium, no momento da desova, muda a 
posição do amplexo, segurando a fêmea na região mediana do abdômen. Esta mudança de posição permite que a cloaca do macho fique mais próxima a da fêmea, provavelmente aumentando a eficiência de fertilização dos ovos, durante a oviposição (veja em POMBAL et al. 1994, discussão sobre a possível vantagem do amplexo inguinal em B. ephippium).

Logo após a oviposição, a fêmea apresenta um comportamento especializado e estereotipado, onde mantém um amplo contato com os ovos. Este comportamento tem como conseqüência visível, grande aderência de partículas do substrato aos ovos, resultando em eficiente camuflagem. Talvez estas partículas também ajudem na manutenção da umidade dos ovos. Algumas das secreções da pele de anfíbios podem ter função bactericida e fungicida (STEBBINS \& COHEN 1995). É possível, então, que o contato prolongado da fêmea de $B$. ephippium com os ovos transfira algumas destas substâncias, de maneira a atenuar as infestações por fungos freqüentes em desovas terrestres (LYNN \& LUTZ 1946a,b; IZECKSOHN et al. 1971).

\section{Características dos ovos e da desova}

A alta umidade, a temperatura e a pluviosidade possivelmente influenciaram a evolução de modos alternativos de reprodução nas florestas tropicais (HöDL 1990). Geralmente, é pressuposto que, em anuros, a desova aquática é a condição reprodutiva primitiva e as desovas terrestres, com desenvolvimento direto, o modo mais derivado (DUELLMAN \& TRUEB 1986; entretanto, veja BOGART 1981 para interpretação diferente).

A família Brachycephalidae, até recentemente, era a única para a qual o modo reprodutivo era desconhecido (Duellman \& TRUeB 1986). Duellman \& TRUeB (1986) acreditam que a desova seja terrestre e o desenvolvimento direto, devido ao grande tamanho e o pequeno número de óvulos nos ovários. Anteriormente, CoCHRAN (1955) descreveu girinos de Hyalinobrachium Ruíz-Carranza \& Lynch, 1991 (Centrolenidae) como sendo de Brachycephalus ephippium (HEYER 1985). GorN et al. (1978), em seu popular livro texto, provavelmente influenciados pelo engano de COCHRAN (1955), citam ovos e girinos aquáticos para a família Brachycephalidae. IZECKSOHN (1971) sugere, baseado em um ovo obtido em laboratório e na análise de ovários, que Psyllophryne didactyla Izeucksohn, 1971 (outro gênero de Brachycephalidae) tenha desenvolvimento direto. HEYER et al. (1990), citando comunicação pessoal de Élio Gôuvea, esclarecem que B. ephippium da região do Itatiaia (RJ) apresentam desenvolvimento direto, o que foi confirmado por POMBAL et al. (1994) e descrito na presente comunicação.

Na seqüência evolutiva de desova aquática para terrestre há uma diminuição do número, aumento do tamanho e redução da pigmentação dos ovos (MARTIN 1967). Os ovos de B. ephippium são grandes, em pequeno número e não pigmentados, o que está de acordo com MARTIN (1967). Todavia, é possível que a despigmentação dos ovos esteja associada aos locais de oviposição, afastados da luminosidade, e não somente ao desenvolvimento direto como sugerido por MARTIN (1967). Como é habitual que anuros com desenvolvimento direto coloquem seus ovos em locais protegidos, provavelmente evitando a dessecação, seria esperado que os ovos fossem despigmentados devido a ausência de luz (como ocorre inclusive com espécies que não apresentam desenvolvimento direto, e.g. MARTINS 1988). 
Brachycephalus ephippium apresenta menor número de ovos por desova e diâmetro do ovo maior quando comparado a outras espécies de desenvolvimento direto (Duellman \& TRUEB 1986). Todavia, espécies tais como Eleutherodactylus guentheri, E. nasutus (A. Lutz, 1925), E. venancioi B. Lutz, 1958 e Myersiella subnigra (Miranda-Ribeiro, 1920) [= microps (Duméril \& Bibron, 1841)] (LYNN \& LUTZ 1946a,b; IZECKSOHN et al. 1971; IZECKSOHN \& ALBUQUERQUE 1972) que apresentam diâmetro e número de ovos igual ou maior que $B$. ephippium também apresentam maior comprimento rostro-anal (HEYER et al. 1990; LUTZ 1925, 1958; NELSON \& LESCURE 1975), o que explicaria as desovas comparativamente maiores, uma vez que espécies maiores apresentam ovos maiores (SALTHE \& DUELLMAN 1973). O aumento no tamanho dos ovos está relacionado à diminuição do seu número (Lutz 1949; Salthe \& Duellman 1973). Desta forma, B. ephippium estaria investindo no maior tamanho dos ovos, em detrimento do número.

\section{Desenvolvimento}

O desenvolvimento fora do meio aquático pode diminuir as pressões de predação e competição (LUTZ 1948, 1949; COE 1974; HöDL 1990). MAGNUSSON \& HERO (1991) postulam que a predação é a principal pressão a determinar a evolução de desovas não aquáticas em anuros.

Nos anuros com desenvolvimento direto e desova terrestre, as espécies com ovos de maior tamanho apresentam um período de desenvolvimento mais longo (Duellman \& TRUEB 1986). Brachycephalus ephippium, quando comparado a outras espécies com o mesmo modo reprodutivo, apresenta um período de desenvolvimento extremamente longo (DUELLMAN \& TRUEB 1986). Todavia, ainda são poucas as espécies de anuros que apresentam desenvolvimento direto, para as quais se conhece o período de desenvolvimento dentro do ovo, principalmente pelas dificuldades de manutenção das desovas em laboratório.

Uma maneira de contornar o problema, de manutenção das desovas em laboratório, é a observação do período de desenvolvimento no campo, como feito neste estudo. Porém, pode haver a limitação de não poder ser observado o desenvolvimento ao longo de todo o período devido a dificuldades de observação do interior dos ovos, principalmente nas desovas semelhantes à de B. ephippium, que é recoberta por partículas do substrato. O ideal seria o acompanhamento, no campo, de algumas desovas concomitantemente ao acompanhamento em laboratório, o que é dificultado pelo encontro pouco freqüente de desovas de anuros com desenvolvimento direto.

Temperaturas diferentes podem causar períodos de desenvolvimento maiores ou menores (JUSTUS et al. 1977; TOWNSEND \& STEWART 1986). Portanto, não seria surpresa se fossem constatadas variações no período de desenvolvimento de B. ephippium ao longo de sua área de distribuição, assim como em outras espécies com desenvolvimento direto que apresentem distribuição ampla.

A cauda dos embriões de anuros com desenvolvimento direto, quando desenvolvida e expandida, tem sido associada a respiração do embrião (NOBLE 1931; Lutz 1948; Duellman \& TRueb 1986; TownSEND \& StewarT 1985). No 
embrião de B. ephippium, a cauda é reduzida e pouco expandida, o que leva a crer que esta estrutura tenha pouca importância na respiração. Não foi observada nos embriões qualquer estrutura a qual pudesse ser atribuída função respiratória. A presença de dente de ovo, antes da presente comunicação, era conhecida unicamente em embriões de anuros com desenvolvimento direto do gênero Eleutherodactylus (DUELLMAN \& TRUEB 1986). O dente de ovo é reduzido e está ausente no jovem de B. ephippium com menos de doze horas de vida, o que permite supor que o dente desprende-se em seguida à eclosão.

AGRADECIMENTOS. Este trabalho foi parte da dissertação de mestrado do autor. Agradeço a Ivan Sazima, pela orientação segura e pelo incentivo durante toda minha formação. W.C.A. Bokermann, C.F.B. Haddad por críticas e sugestões apresentadas a dissertação. R. Fernandes pela leitura do manuscrito e pela ajuda com o abstract. I. Sazima pelas fotografias das figuras 5 e 6. C.F.B. Haddad, O.C. Oliveira, E.C.P. Pombal, R.P. Pombal, I. Sazima e M. Rossato pela ajuda nos trabalhos de campo. P.S. Oliveira permitiu a utilização do estereomicroscópio para realização das fotografias. A FUJB e FAPERJ pelos auxílios concedidos.

\section{REFERÊNCIAS BIBLIOGRÁFICAS}

BOGART, J.P. 1981. How many times has terrestrial breeding evolved in anuran amphibians? Monit. Zool. Ital. 15 (3): 29-40.

Cochran, D.M. 1955. Frogs of southeastern Brazil. U.S. Nat. Mus. Bull. 206: $1-423$.

CoE, M. 1974. Observations on the ecology and breeding biology of the genus Chiromantis (Amphibia: Rhacophoridae). Jour. Zool., London, 172: 13-34.

DUELLMAN, W.E. \& L. TRUEB. 1986. Biology of amphibians. New York, McGrawHill, 670p.

FRost, D.R. 1985. Amphibian species of the world. A taxonomic and geographic reference. Lawrence, Allen Press Inc., 732p.

Giaretta, A.A. \& R. Sawaya. 1998. Second species of Psyllophryne (Anura: Brachycephalidae). Copeia 1998 (4): 985-987.

GoIN, C.J.; O.B. GorN \& G.R. ZUG. 1978. Introduction to herpetology. San Francisco, Freeman, $3^{\text {rd }}$ ed., 378 p.

HEYER, W.R. 1985. Taxonomic and natural history notes on frogs of the genus Centrolenella (Amphibia: Centrolenidae) from southeastern Brazil and adjacent Argentina. Pap. Avulsos Zool., São Paulo, 36 (1): 1-21.

Heyer, W.R.; A.S. Rand; C.A.G. Cruz; O.L. Peixoto \& C.E. Nelson. 1990. Frogs of Boracéia. Arq. Zool., São Paulo, 31 (4): 231-410.

HöDL, W. 1990. Reproductive diversity in amazonian lowland frogs, p.41-60. In:

W. HANKE (Ed.) Biology and physiology of amphibians. Stuttgart, Gustav Fischer.

IZECKSOHN, E. 1971. Novo gênero e nova espécies de Brachycephalidae do Estado do Rio de Janeiro, Brasil (Amphibia, Anura). Bol. Mus. Nac. (Zool.), Rio de Janeiro, 280: 1-12.

IZECKSOHN, E. \& S.T. AlBuQUERQUE. 1972. Algumas observações sobre o desen- 
volvimento de Eleutherodactylus venancioi B.Lutz (Amphibia, Anura). Arq. Univ. Fed. Rural do Rio de Janeiro: 13-15.

IZECKSOHN, E.; J. JIM; S.T. ALBUQUERQUE \& W.F. MENDONÇA. 1971. Observações sobre o desenvolvimento e os hábitos de Myersiella subnigra (MirandaRibeiro) (Amphibia, Anura, Microhylidae). Arq. Mus. Nac., Rio de Janeiro, 54: 69-73.

Justus, J.T.; M. SANDOMIR; T. UrquiHart \& B.O. EWAN. 1977. Developmental rates of two species of toads from the desert southwest. Copeia 1977 (3): 592-594.

LEHNER, P.N. 1996. Handbook of ethological methods. Cambridge: Cambridge University Press, $2^{\text {nd }}$ ed., $672 \mathrm{p}$.

LuTZ, A. 1925. Batraciens du Brésil. Comptes rendus 93 (2): 211-214.

1948. Ontogenetic evolution in frogs. Evolution 2: 29-39.

1949. A ontogênese dos anfíbios anuros e a evolução terrestre dos vertebrados. Bol. Mus. Nac. (Zool.), Rio de Janeiro, 91: 1-10.

1958. Anfíbios novos e raros das serras costeiras do Brasil. Mem. Inst. Oswaldo Cruz 56 (2): 373-399.

LYNN, W.G. \& B. LUTZ. 1946 a.The development of Eleutherodactylus guentheri Stdnr. 1864 (Salientia). Bol. Mus. Nac. (Zool.), Rio de Janeiro, 71: 1-46. 1946b. The development of Eleutherodactylus nasutus Lutz (Salientia). Bol. Mus. Nac.(Zool.), Rio de Janeiro, 79: 1-30.

Magnusson, W.E. \& J.M. Hero. 1991. Predation and the evolution of complex oviposition behaviour in Amazon rainforest frogs. Oecologia 86: 310-318.

MARQUeZ, R. \& P. VERREL. 1991. The courtship and mating of the Iberian midwife toad Alytes cisternasii (Amphibia: Anura: Discoglossidae). Jour. Zool., London, 225: 125-139.

MARTIN, A.A. 1967. Australian anuran life histories: some evolutionary and ecological aspects, p.175-191. In: A.S. WEATHERLEY (Ed.). Australian inland waters and their fauna. Canberra Univ. Press.

Martins, M. 1988. Biologia reprodutiva de Leptodactylus fuscus em Boa Vista, Roraima (Amphibia: Anura). Rev. Brasil. Biol. 48 (4): 969-977.

Nelson, G.E. \& J. LesCURE. 1975. The taxonomy and distribution of Myersiella and Synapturanus (Anura: Microhylidae). Herpetologica 31 (4): 389-397.

NoBLE, G.K. 1931. The biology of the amphibia. New York, Mc Graw-Hill Book Company Inc., $577 \mathrm{p}$.

PomBal JR., J.P.; I. SAZIMA \& C.F.B. HADDAD. 1994. Breeding behavior of the pumpkin toadlet, Brachycephalus ephippium (Brachycephalidae). Jour. Herpetol. 28 (4): 516-519.

POMBAL JR., J.P.; E.M. WistuBA \& M.R. BornSCHEIN. 1998. A new species of brachycephalid from the Atlantic Rain Forest of Brazil. Jour. Herpetol. 32 (1): 70-74.

SAlthe, S.N. \& W.E. Duellman. 1973. Quantitative constraints associated with reproductive mode in anurans, p.229-249. In: J.L. VIAL (Ed.). Evolutionary biology of anurans. Comtemporary research on major problems. Columbia, Univ. Missouri Press, 470p. 
StebBins, R.C. \& N.W. CoHEN. 1995. A natural history of amphibians. Princeton, Princeton University Press, 316p.

TOWNSEND, D.S. \& M.M. STEWART. 1985. Direct development in Eleutherodactylus coqui (Anura: Leptodactylidae): a staging table. Copeia 1985 (2): 423-436. . 1986. The effect of temperature on direct development in a terrestrial-breeding, neotropical frog. Copeia 1986 (2):520-527.

Recebido em 19.III.1998; aceito em 31.VIII.1999. 